\title{
Review on Factors Affecting Quality of B2C Website
}

\author{
Tanushree Chauhan ${ }^{1}$, Pankaj Dalal ${ }^{2}$ \\ ${ }^{1}$ (M.Tech Scholar, Software Engineering) \\ ${ }^{2}$ (Associate Professor, Software Engineering)
}

\begin{abstract}
There has been a phenomenal growth in e-commerce in last few years and it still growing. The most successful and experienced companies related to E-Commerce realize that key determinant of success and failure of any website are not merely a web presence or low price but the delivery on high quality websites along with its security. A framework and model is required to attain the desired quality of website. Evaluation criteria include design, security, usability and performance for websites etc. This paper provides a review based on different authors to establish Quality. The main goal are identifying factors through different research papers and categorizing these factors.
\end{abstract}

Keywords: - E-commerce, Quality, Security, Trustworthiness, Usability

\section{INTRODUCTION}

In virtual enterprise, variety of website increased with proportionally increase in number of internet users. Most of the contact with customer hinges on the interaction between customer and websites. Websites serve different facilities such as trading products, e-banking, e-ticketing, selling and buying online goods and many more. All these online activity require security to make the data confidential from real world. E-commerce is the most pervasive and prominent type for online communication in case of trading of goods and services. Through internet, the companies as well as manufactures can trade globally and can find business throughout the world by putting less amount of investment. [1]

\section{LITERATURE REVIEW}

Many authors concluded different factor which are essential in case of website development. Many research papers have evaluated the existing quality models and determined the factors related to Ecommerce website and designed a theoretical model [2] [10] [6]. Some papers have determined the key factors that affect the quality [7] [8] [12], design [9], Security [16], Usability [15] [8], Information Assurance [14], Trust [17] [5] and Accessibility [18]. The various issues regarding quality control and maintenance of web sites while designing and developing were also recommended [13]. Most of the work done is based on survey in which data were collected by distributing questionnaire to the end users [17] [15] [12] [5] [9] [7] [8] [10] [6]. A met metric suggests what metrics should be used in Ecommerce [4]. Different strategies and business models propose different metrics to measure performance of Ecommerce system [4].

By understanding the quality dimensions, an organization will get better chance for gaining more business and serving its stakeholders [10]. The model categorizes and ranks the factors that affect the quality of Ecommerce website [7].

Designing a successful B2C system requires fulfillment of specific functional requirements [4]. Quality in general, is often underestimated especially at the first stages of the system design/development [4]. In the initial phases, architecture and implementation of the product is the main concern of the designer while Quality of product comes under testing phase. The most common measure of quality is number of bugs found and removed from the product [3].

Quality can be examined from two different perspectives, one on the basis of developers and the other according to end-users point of view. The technical specifications of a system predicts consumer's acceptance of Ecommerce system in developer perspective [4]. While End-user, especially in B2C systems, sets the quality attributes that influence shopping decision. In order to ensure the production of high quality Ecommerce systems, it is important to be able to assess the quality of B2C systems from the point of the user as well [4]. Websites have different factors that generated from the process of user and system interaction and overall user satisfaction and that they can serve the development and maintenance phases of website creation [9].

Liu et al. [31] examined the web sites of Fortune 500 companies to identify how they were using the web for interacting with their customers. They found that $95 \%$ use web sites to provide information on their products and services, and about $26 \%$ do some kind of electronic transactions. Ho examined 1800 web sites from varied industries across multiple nations. 
The items selected in the questionnaire can be used in the development process, especially for trading sites, which have consistently been found to be a problem [9]. Yang [10] suggests an instrument that measures users perceived service quality of IP web portals having 19 items throughout five factors. Each factors have a significant impact on overall service quality [10]. Jones and Biasiotto [29] examined the web sites of 160 retailers and described how store-based retailers use the Internet.

Stefani[2]

presents a model for the quality of Ecommerce systems, which consists of two alternative evaluation processes, the forward use and the backward use. Its backward use helps the developers to identify the importance feature based on the end-users perception of quality and subsequently value the association of each probability measure to technology components of the system [2].

Hoffman et al. [26] provided six categories for classifying commercial web sites, namely: online storefront, Internet presence, content, mall, incentive site, and search agent. Spiller and Lohse [36] focused on online shopping stores and classified them into five categories: superstores and promotional stores.

The research conducted by Osama [7], identified and ranks all the factors. Those factors that score above 50 ranks were considered for our research. Factors like conceptual reliability was studied in detail and incorporated in our research. Study conducted by Dutton [17], propose that there is a misalignment between what users require and what developers of Ecommerce systems actually provide. E banking Portals or websites is the most frequently used Ecommerce sites used for transactions by consumers. Customer satisfaction and customer retention increase with increase in quality of E- banking portals.

Many articles are based on experiences of one or a few organizations, and give a descriptive account of organizational experiences in deploying B2C web sites [21, 23, 37, 38]. Articles have also focused on reporting existing status of B2C e-commerce $[22,25,39]$, forecasting and providing general guidelines for designing and managing $\mathrm{B} 2 \mathrm{C}$ web sites $[20,24,33]$

The study conducted by Zhilin [10] has determined that there are five service quality dimensions perceived by users of an IP Web portal. These were consistent with our original factors except for the security/privacy factor. The model proposed by Jingling [6], pays attention to the user's point of view and analyzes user's quality requirements. The following quality factors have been identified: Easy to use (Applicable information, Navigation), Reliability (Accuracy, Authority), Responsiveness (Response, Feedback), Assurance (Credibility, Safety) and Good Experience (Aesthetics, Individuation).

Another group of researchers attempted to develop frameworks and models for B2C e-commerce. Angerhn and Meyer [19] examined the banking industry to offer some guidelines for developing Internet strategies. Nour and Fadlalla [34] provided a framework for formulating web-based marketing strategies. Johnson, Hyde and Ambrose [28] developed a sociotechnical framework for assessing the benefits of electronic retailing. Lohse and Spiller [32] reviewed user interface features in electronic shopping and made several recommendations for developing a B2C web site. Liu and Arnett [30] proposed a framework for designing quality B2C web sites. Hoffman and Novak [27] analyzed a few case studies to recommend several measures for improving B2C web sites. Patrick and Joe [35] extended the conventional model of consumer buying behavior to online purchases, and made recommendations for improving online commerce.

\section{CONCLUSION}

This paper has determined the factors that assess the quality of an E-commerce website such as usability, reliability, trustworthiness, accessibility, security, efficiency etc. The list of attributes was derived from the specialized literature. The survey as well as analysis study also describe a greater understanding of these inter-related sub-factors which influence the main quality factors. The results of the literature review provide an important foundation for the understanding of quality in E-commerce websites that will allow developers to assess the strengths and weaknesses of their sites in order to know where to focus further development to achieve the high quality needed for E-commerce success.

\section{FUTURE WORK}

These paper will conclude some essential factors which will be used for B2C website designing, this will help further to improve few Quality metric of B2C website.

\section{REFERENCES}

[1] Pai, G.J.; Dugan, J.B.; Fraunhofer Inst., "Empirical Analysis of Software Fault Content and Fault Proneness Using Bayesian Methods", Software Engineering, IEEE Transactions Volume 33 Issue 10.

[2] Antonia Stefani and Michalis Xenos, "E-Commerce System Quality Assessment using a Model based on ISO 9126 and Belief Networks", Software Quality Journal, Volume 16, Number 1.

[3] Sunghun Kim, "Adaptive Bug Predictions by Analyzing Software History", University of California, Santa Cruz, 2006. 
[4] A.Stefani, M. Xenos, "Meta-metric Evaluation of E-commerce-related Metrics", Electronic Notes in Theoretical Computer Science (ENTCS) Volume 233, March 2009 Pages: 59-72.

[5] Mark A. Serva, John "Skip" Benamati, Mark A. Fuller, "A Trustworthiness in B2C E-Commerce: An Examination of Alternative Models”, ACM SIGMIS Database, Volume 36, Issue 3 , Summer 2005, 89 108.

[6] Chang Jinling; Song Tong; Li Chuncan; Song Tao, "Modeling E-Commerce Website Quality with Quality Function Deployment", 2009 IEEE International Conference on e-Business Engineering, 21-23 Oct. 2009, $417-422$.

[7] Osama Mohammed Ahmad Rababah and Fawaz Ahmad Masoud, "Key Factors for Developing a Successful E-commerce Website", Communications of the IBIMA Vol. 2010, Article ID 763461, 9 pages. http://www.ibimapublishing.com/journals/CIBIMA/cibima.html

[8] Isaac J. Gabriel, "Usability Metrics for Measuring Usability of Business-to-Consumer (B2C) ECommerce Sites", In Proceedings of the 6th Annual ISOnEworld Conference, April 11-13, 2007, Las Vegas, NV, 74.1-74.19.

[9] Moshe Zviran, Chanan Glezer, Itay Avni, "User satisfaction from commercial web sites: The effect of design and use, Information and Management”, v.43 n.2, p.157-178, March 2006.

[10] Zhilin Yang, Shaohan Cai, Zheng Zhou, Nan Zhou, "Development and validation of an instrument to measure user perceived service quality of information presenting Web portals", Information \& Management, Volume 42, Issue 4, May 2005, Pages 575-589.

[11] Anjali bhargav, Bharat bhargav, "Measurements and quality of service issues electronic commerce software", Application-Specific Systems and Software Engineering and Technology, 1999. ASSET '99, Proceedings, 1999, $26-33$.

[12] C. Ranganathan, Shobha Ganapathy, "Key dimensions of business-to-consumer web sites', Information and Management Volume 39, Issue 6, May 2002, 457 - 465, 2002.

[13] Jayanta Bhattacharjee, Manoj Kumar Sinha , Manoj Kumar K., "Quality Control Issues For Design, Development and Maintenance of Web Sites”, 4th International Convention CALIBER-2006, Gulbarga, 2-4 February, 2006.

[14] Dan J. Kim, Natarajan Sivasailam and H. Raghav Rao., "Information Assurance in B2C Websites for Information Good/Services", Electronic Markets, Volume 14, Issue 4 December 2004 , pages $344-359$.

[15] Ritu Agarwal, Viswanath Venkatesh, “Assessing a Firm's Web Presence: A Heuristic Evaluation Procedure for the Measurement of Usability”, Information Systems Research, Vol. 13, No. 2, June 2002, pp. 168-186.

[16] Hossein Bidgoli, "Security Considerations in an E-commerce Environment: Guidelines for Success", Proceedings, Western Decision Sciences Institute, Los Vega, Nevada, April, 2002.

[17] Philip D Dutton, "Trust-Issues in the Design and Development of Electronic Commerce Systems", Bachelor's thesis, Griffith University, School of Computing and Information Technology, 2000.

[18] Oreste Signore, Barbara Leporini, "Web Accessibility: Principles, International Context and Italian Regulations", Proceedings of CMG Italia, Conferenza annuale, Pisa, 2004.

[19] A.A. Angehrn, J.F. Meyer, "Developing Internet strategies: insights from the banking sector", Information Systems Management (1997) 37 \pm 43 .

[20] J.D. Calkins, M.J. Farello, C.S. Shi, "From retailing to e- tailing", McKinsey Quarterly (2000) 1; http://www.mckinsey- quarterly.com/electron/reet00.asp.

[21] Survey reveals Internet shopping habits, Direct Marketing (2000).

[22] O.A. El Sawy, A. Malhotra, S. Gosain, K.M. Young, "IT- intensive value innovation in the electronic economy: insights from Marshall Industries", MIS Quarterly 23 (3), 1999, pp. 305 \pm 336.

[23] J.L. Gogan, "The web's impact on selling techniques: historical perspective and early observations",

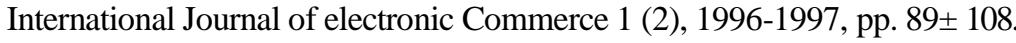

[24] J. Ho, "Evaluating the world wide web: a global study of commercial sites", Journal of Computer Mediated Communication, 3(1) (1997); http://www.ascusc.org/jcmc/vol3/ issue1/ho.html.

[25] D.L. Hoffman, T.P. Novak, P. Chaterjee, "Commercial scenarios for the web: opportunities and challenges",

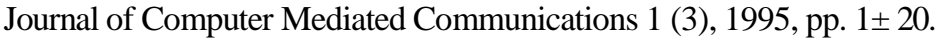

[26] D.L. Hoffman, T.P. Novak, 'How to acquire customers on the web", Harvard Business Review, Boston (2000) $179 \pm 183$.

[27] G. Johnson, M. Hyde, P. Ambrose, "Is electronic retailing the glorified catalog of tomorrow", Proceedings of the America's Conference of Association of Information Systems, Baltimore, Maryland, MD, $14 \pm 16$ August 1998.

[28] K. Jones, M. Biasiotto, “Internet Retailing: Current Hype or Future Reality?" Research report, Centre for the Study of Commercial Activity, Ryerson Polytechnic University, Tor- onto, 1997.

[29] C. Liu, K Arnett, "A proposed research model for appraisal and evaluation of the design of web sites in the 
context of electronic commerce", Proceedings of the America's Conference of Association of Information

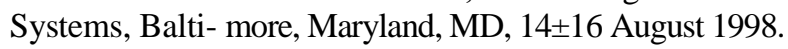

[30] C. Liu, K. Arnett, L. Capella, R. Beatty, "Web sites of the Fortune 500 companies: facing customers through home pages", Information \& Management 31, 1997, pp. 335 \pm 345 .

[31] G.L. Lohse, P. Spiller, Electronic shopping, Communications of the ACM 41 (7), 1998, pp. $81 \pm 87$.

[32] M. Morris, R.J. Hinrichs, “Web Page Design: A Different Multimedia”, Sunsoft Press, Mountain View, CA, 1996

[33] M.A. Nour, A. Fadlalla, “A framework for web marketing strategies”, Information Systems Management

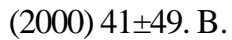

[34] Patrick, P. Joe, “Consumer purchasing on the Internet: processes and prospects", European Management Journal $16(5), 1998$, pp. $600 \pm 610$.

[35] J. Starne, Winning glances, CIO Magazine $\quad$ (1997); http:// www.cio.com/archive/webbusiness/080197 customer.html

[36] A. Stuart, Leaders of the pack, CIO Magazine (1999); http:// www.cio.com/archive/webbusiness/070199_Internet.html

[37] US Department of Commerce, The Emerging Digital Economy II, 1999; http://www.ecommerce.gov/ede.

[38] N. Venkatraman, "Five steps to a dotcom strategy: how to find your footing on the web", Sloan Management

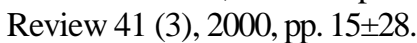

